\title{
FLORA DE GRÃO-MOGOL, MINAS GERAIS: MALVACEAE ${ }^{1}$
}

\author{
GERLENI LOPES ESTEVES* \& ANTONIO KRAPOVICKAS**
}

\author{
*Instituto de Botânica, Caixa postal 4005, 01061-970 - São Paulo, SP, Brasil. \\ **Instituto de Botánica del Nordeste, Casilla de Correo, 209, 3400 - Corrientes, Argentina.
}

ESTEVES, G. L. 1986. A Ordem Malvales na Serra do Cipó, Minas Gerais, Brasil. Dissertação de Mestrado. Universidade de São Paulo. São Paulo.

ESTEVES, G.L. 2001. O gênero Pavonia Cav. (Malvaceae) na região Sudeste do Brasil. Boletim do Instituto de Botânica 15: 125-194.

GÜRKE, M. 1892. Malvaceae II. In C.F.P. Martius \& A.W. Eichler (eds.). Flora brasiliensis. Fried. Fleischer. Lipsiae, vol. 12, pars. 3, p. 457- 586, tab. 81-114.

SCHUMANN, K.M. 1891. Malvaceae I. In C.F.P. Martius \& A.W. Eichler (eds.). Flora brasiliensis. Fried. Fleischer. Lipsiae, vol. 12 , pars. 3 , p. $253-456$, tab. 51- 80 .

1. Flores com epicálice.

2. Estiletes em número igual ao de carpelos

Hibiscus nanuzae

2'. Estiletes em número dobro ao de carpelos.

3. Lâminas foliares com nectário na face abaxial; mericarpos aculeados na face dorsal

Urena lobata

3'. Lâminas foliares sem nectário; mericarpos sem acúleos.

4. Bractéolas do epicálice diferenciadas morfologicamente em lâmina e pé; pétalas inteiramente amarelas

Peltaea obsita

4'. Bractéolas do epicálice sem diferenciação morfológica; pétalas amarelas ou róseas a vermelhas, com mancha basal vinácea ou branca

Pavonia

5. Epicálice com 4-7 bractéolas ovadas a suborbiculares.

6. Pétalas amarelas com mancha basal vinácea; estames com partes livres concentradas na porção apical do tubo; mericarpos múticos; sementes lisas

P. grazielae

6'. Pétalas róseas com mancha basal vinácea; estames com partes livres distribuídas em grupos ao longo do tubo; mericarpos mucronados; sementes estriadas

P. garckeana

5'. Epicálice com 6-25 bractéolas lineares a elípticas.

7. Pétalas amarelas.

8. Plantas prostradas; lâminas foliares ovadas a triangulares, base cordado-sagitada a cordado-hastada; epicálice com 13-17 bractéolas; mericarpos longamente rostrados P. cancellata

8'. Plantas eretas; lâminas foliares ovadas, base cordada; epicálice com 6-8 bractéolas; mericarpos não rostrados P. sidifolia

7'. Pétalas róseas a vermelhas.

9. Pétalas vermelhas com nervuras amarelas, 3-3,5 cm compr.; tubo estaminal ereto, 2,5-2,8 cm comp.; mericarpos não verrucosos P. aschersoniana

9'. Pétalas róseas a vermelhas com mancha basal branca, 1,5-2,5 cm compr.; tubo estaminal inclinado, 5-8mm comp.; mericarpos verrucosos P. rosa-campestris

$1 '$. Flores sem epicálice.

10. Mericarpo com 3-5 sementes Abutilon

11. Flores solitárias; cálice 18-28 mm compr., 5-giboso na base; tubo estaminal 10-15 mm compr.; óvulos 4-5 por carpelo A. monteiroi

\footnotetext{
${ }^{1}$ Trabalho realizado conforme o planejamento apresentado por Pirani et al. (2003). Bol. Bot. Univ. São Paulo 21(1): 1-24.
} 
11'. Inflorecências paniculiformes; cálice 3-4 mm compr., não giboso na base; tubo estaminal 2-3mm compr., óvulos 3 por carpelo A. ramiflorum

10'. Mericarpo com 1 semente Sida

12. Mericarpos 5.

13. Ramos com tricomas estrelados; lâminas foliares velutinas a vilosas; mericarpos pubescente-estrelados na porção apical Sida $\mathrm{sp} 1$

13'. Ramos sem tricomas estrelados; lâminas foliares pubescentes; mericarpos pubescente-glandulares na porção apical S. aurantiaca

12'. Mericarpos mais de 5.

14. Mericarpos múticos Sida $\mathrm{sp} 2$

14'. Mericarpos aristados; aristas com tricomas simples retrorsos.

15. Lâminas foliares lineares a estreitamente elípticas, 1-nérveas S. angustissima 15'. Lâminas foliares oblongo-ovadas a ovadas, 5-7-palmatinérveas.

16. Lâminas foliares oblongo-ovadas, 17-21 x 7,5-9 mm, geralmente vinácea na margem; mericarpos com longos tricomas simples na porção apical S. cerradoensis 16'. Lâminas foliares ovadas, 20-30 x 17-20 mm, margem não vinácea; mericarpos com tricomas simples pequenos na porção apical S. cordifolia

\section{Abutilon Mill.}

Arbustos. Folhas de lâminas inteiras a lobadas, sem nectários. Flores solitárias ou reunidas em inflorescências pauci a multifloras; epicálice ausente; cálice cupuliforme, 5-lobado; pétalas 5, obovadas; tubo estaminal com partes livres de estames concentradas na sua porção apical; gineceu 5-10 carpelos; óvulos 3-5 por carpelo; estiletes em número igual ao de carpelos; estigmas capitados. Fruto esquizocárpico; mericarpos 6-10, lisos e glabros nas partes onde se tocam, sem divisão ou constrição interna, deiscentes na face dorsal, múticos ou rostrados; sementes 3-5 por mericarpo, reniformes.

1.1. Abutilon monteiroi Krapov., Hickenia 1(51): 273, fig. 3. 1982.

Arbustos 1,5- 2 m alt.; ramos cilíndricos, velutinos, tricomas estrelados amarelos. Folhas de lâminas inteiras, raramente 3-lobadas, 4,3-11,7 cm comp., 2,2-8,4 cm larg., discolores, ovadas, ápice agudo, base cordada, velutinas em ambas as faces, tricomas estrelados; pecíolos 1,5-5 cm comp. Flores solitárias, axilares; pedicelos 4-5,5 cm comp.; cálice 1,8- 2,8 cm comp., verde-claro, 5-giboso na base; pétalas 1,8-3 cm comp., alvas a cremes, pilosas na base; tubo estaminal 1-1,5 cm compr.; estiletes 7-10. Mericarpos 7-10, múticos, nigrescentes, tomentosos, tricomas estrelados; sementes 4-5 por mericarpo. (Fig. 1. A-B ).

Cordeiro et al. CFCR 842 (SPF); Silva et al. CFCR 12519 (CTES, SP, SPF); Hatschbach \& Nicolack 54157 (CTES, MBM, SPF).

Conhecida pelas coleções da Cadeia do Espinhaço, Minas Gerais. Em Grão-Mogol vive no campo rupestre entre rochas, em altitudes de 950 a 120a0m. Floresce e frutifica o ano todo. É facilmente reconhecida pelas flores solitárias de pétalas grandes (até $3 \mathrm{~cm}$ de comprimento) e cálice 5 -giboso na base.
1.2. Abutilon ramiflorum A. St.-Hil., Fl. bras. merid. 1: 156. 1825.

Arbustos 1,8-3 m alt.; ramos pubérulos, tricomas simples e estrelados, ramos de primeira ordem triangulares. Folhas de lâminas inteiras, 5-10 cm compr., 5,5-10 cm larg., ovadas a suborbiculares, ápice agudo, base cordada, margem serreada. Inflorescências paniculiformes; pedicelos 5-11 mm compr.; cálice 3-4 mm compr., não giboso na base, profundamente lobado; pétalas 5-7mm compr., amarelo-claras, glabra na base; tubo estaminal 2-3mm compr.; estiletes 6-8. Mericarpos 6-8, curtamente rostrados, com tricomas estrelados; sementes 3 por mericarpo. (Fig. 1. C).

\section{Souza et al. 25759 (ESA, SP).}

Distribui-se na Bolívia, Paraguai e no Brasil em Minas Gerais e São Paulo. Em Grão-Mogol ocorre na transição mata ciliar-cerrado. Flores e frutos de junho a agosto. Pode ser reconhecida pelas flores pequenas, menores que $1 \mathrm{~cm}$ de comprimento, reunidas em inflorescências paniculiformes, com cálice profundamente lobado e tubo estaminal curto, com 2-3mm de comprimento. 


\section{Hibiscus L.}

Subarbustos a arbustos, não aculeados. Folhas de lâminas inteiras, com 1 nectário sobre a nervuras média na face abaxial. Flores solitárias, axilares; epicálice presente, com bractéolas inteiras, livres entre si; cálice 5-lobado, cupuliforme, com um nectário sobre as nervuras principais de cada lobo; pétalas 5, obovadas; tubo estaminal 5-denteado no ápice, partes livres dos estames distribuídas em grupos ao longo do tubo; ovário 5-carpelar, 5-locular, lóculos multiovulados; estiletes 5; estigmas capitados. Fruto cápsula loculicida; sementes numerosas.

2.1. Hibiscus nanuzae Krapov. \& Fryxell. Bonplandia 13: 92, 2004.

Arbusto ca. 1,5m alt.; ramos recobertos de tricomas estrelados amarelos híspidos; lâminas discolores, 5-9 cm comp., 6,3-9 cm larg., orbiculares, ápice agudo, base arredondada a subcordada, margem serreada, nervação arroxeada na face abaxial; nectário 1, oblongo; estípulas ca. $8 \mathrm{~mm}$ comp., filiformes; bractéolas do epicálice ca. 10, linear-subuladas, bifurcadas na parte apical, menores que o cálice; cálice 1,5$1,7 \mathrm{~cm}$ compr., cupuliforme, externamente hirsuto, tricomas estrelados, nectário globoso; pétalas 5-6 cm compr., róseas; tubo estaminal ca. 4,5 cm compr.; carpelos 4-ovulados. Cáp- sula ovóide, ca. 2 cm compr., glabra; sementes com escamas pectinadas. (Fig. 1. I).

Mello-Silva et al. 758 (CTES, SP, SPF).

Material adicional examinado: Minas Gerais, Botumirim, P. Fiaschi et al. 184 (SP, SPF); Cristália, Morro do Chapéu, J.R. Pirani et al. CFCR 8923 (SPF); Diamantina, G. L. Esteves 2329 (CTES, SPF).

Distribuída na Cadeia do Espinhaço, em Minas Gerais, desde Grão-Mogol até Diamantina, no Campo rupestre. Em GrãoMogol foi encontrada próximo à nascente do Rio Ventania, em solo arenoso, ca. $920 \mathrm{~m}$ s.m. Caracteriza-se pelas folhas pecioladas, bractéolas furcadas, cálice hirsuto e cápsula glabra.

\section{Pavonia Cav.}

Ervas, subarbustos ou arbustos. Folhas de lâminas inteiras, sem nectários. Flores geralmente solitárias, axilares; epicálice 4-25 bractéolas, livres entre si, não diferenciadas morfologicamente em pé e lâmina, lineares, elípticas a orbiculares; cálice 5-lobado, tubuloso, cupuliforme ou campanulado; pétalas 5, obovadas, diversamente coloridas, com mancha basal; tubo estaminal 5-denteado no ápice, partes livres dos estames diversamente distribuídas ao longo do tubo; ovário 5-carpelar, carpelos uniovulados; estiletes 10; estigmas capitados. Frutos esquizocárpicos; mericarpos 5, múticos a rostrados, trígonos, face dorsal nervado-reticulada, faces laterais lisas e glabras nas partes onde se tocam; sementes reniformes ou obovóides, lisas ou estriadas.

3.1. Pavonia aschersoniana Gürke in Mart., Fl. bras. 12(3): 518 , t. 100 , f. $1,1892$.

Arbustos ca. 1,80 m alt., viscosos; ramos velutinos, tricomas estrelados e glandulares. Folhas de lâminas 4,5-6,2 cm compr., 3-4,9 cm larg., discolores, ovadas, ápice agudo, base cordada; pecíolos 2,5-6cm compr. Flores solitárias, vistosas; epicálice com 17-20(-25) bractéolas, 2,2-2,7 cm compr., lineares, longamente ciliadas; cálice 1,2-1,3 cm compr., cupuliforme, lobos 2-denteados, ciliados; pétalas 3-3,5 cm compr., vermelhas com nervuras amarelas; tubo estaminal $2,5-2,8 \mathrm{~cm}$ compr., ereto, estames com partes livres no $1 / 3$ apical do tubo. Mericarpos subovóides, nigrescentes, curtamente rostrados, não verrucosos; sementes lisas, reniformes. (Fig. 2. F-G)

\section{Pirani et al. CFCR 12985 (CTES, SPF).}

Conhecida apenas pelas coleções da Cadeia do Espinhaço, Bahia e Minas Gerais. Neste último estado ocorre desde Grão-Mogol até Virgem da Lapa. Caracteriza-se pelas folhas discolores, ovadas com base cordada, flores vistosas de pétalas vermelhas com nervuras amarelas. Além disso, pode ser facilmente distinta pelo epicálice composto por 17 a 25 bractéolas, o maior número encontrado no gênero (Esteves 2001), ciliadas e medindo quase o dobro do comprimento do cálice. A presença de rostro nos mericarpos também é um caráter marcante nessa espécie (Fig. 2G).

\subsection{Pavonia cancellata ( L.) Cav., Diss. 3: 135, 1787.}

Ervas prostradas, viscosas; ramos ascendentes, pubescentes, tricomas glandulares e estrelados, ocasionalmente tricomas simples, patentes, esparsos. Folhas de lâminas 3-5,8 cm compr., 2,4-3,9 cm larg., ovadas a triangulares, ápice agudo, base cordado-sagitada a cordado-hastada, margem crenadoserreada a serreada; pecíolos $8-25 \mathrm{~mm}$ compr. Flores solitárias; vistosas, epicálice 13-17 bractéolas, 1,1-1,5 cm compr., lineares, longamente ciliadas; cálice 6-9 mm compr., campanulado; pétalas 2,5-2,9 cm compr., amarelas com mancha basal vinácea; tubo estaminal 1,5-1,8 cm compr., partes livres dos estames distribuídas por todo o tubo. Mericarpos obovóides, longamente rostrados, verrucosos, estreitamente alados nas margens, rostros $0,5-3 \mathrm{~mm}$ compr.; sementes lisas, pubérulo-estreladas. (Fig. 2. H-J). 


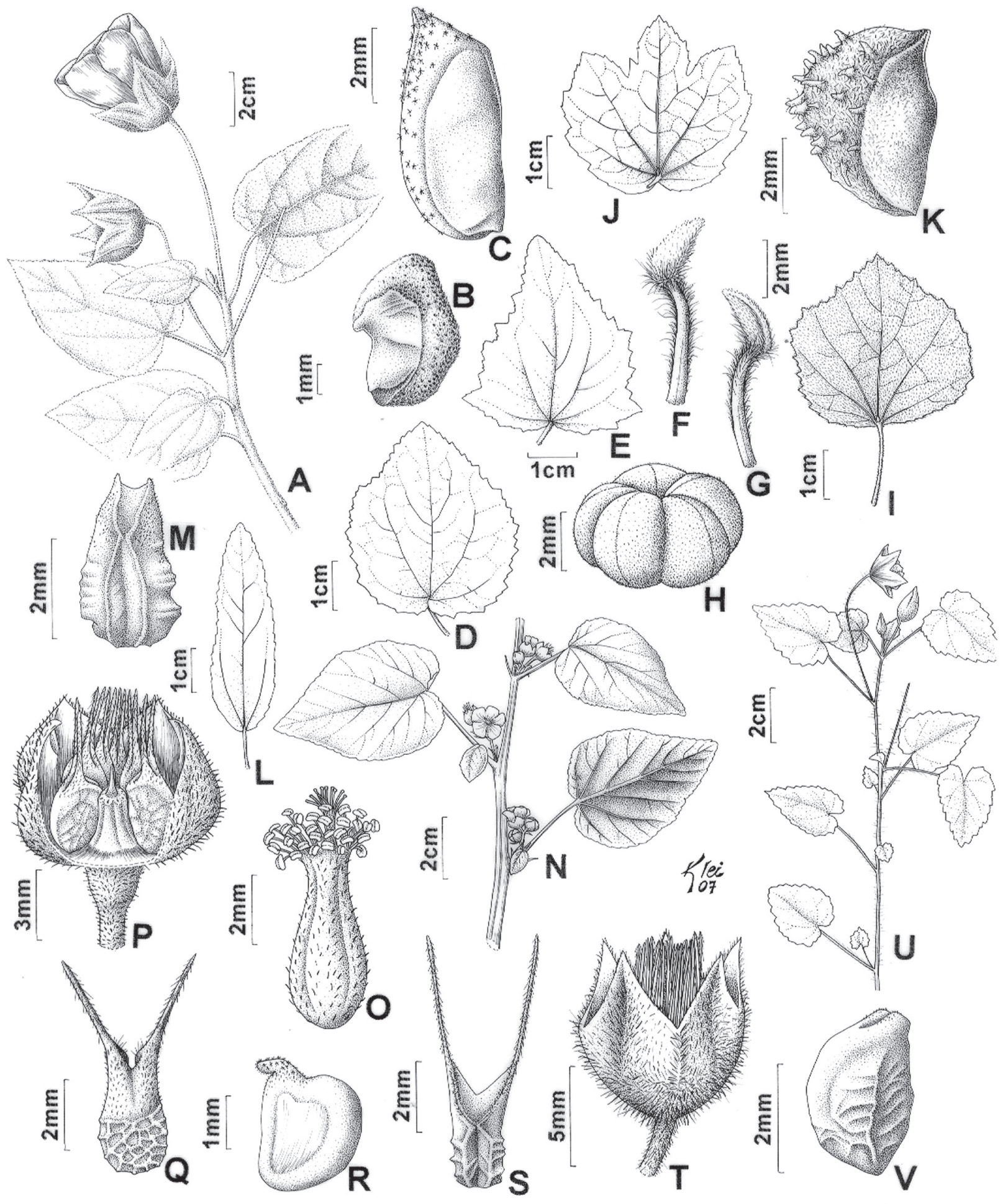

Fig. 1. MALVACEAE. A-B. Abutilon monteiroi: A. Ramo com flores. B. Mericarpo, vista lateral. C. A. ramiflorum: Mericarpo, vista látero-dorsal. D-H. Peltaea obsita: D-E. Folhas, face adaxial. F-G. Bractéolas do epicálice. H. fruto com 5 mericarpos. I: Hibiscus nanuzae: Folha, face abaxial, mostrando nectário na base da lâmina. J-K. Urena lobata: J. Folha, vista abaxial, mostrando nectário na base da lâmina. K .Mericarpo, vista dorso-lateral. L-M. Sida sp2: L. folha, face adaxial. M. Mericarpo, vista dorsal. N-R. Sida cordifolia: N. Ramo com flores. O. Tubo estaminal. P. Fruto, mostrando os mericarpos presos a columela central. Q. Mericarpo, vista dorsal. R. Semente. S. S. angustissima: Mericarpo, vista dorsal. T. S. cerradoensis: Cálice com fruto, mostrando a parte apical das aristas dos mericarpos. U-V. Sida sp1: U. Ramo com flores. V. Mericarpo, vista látero-dorsal. (N-R: extraídos de Esteves 1986). 
Esteves et al. CFCR 13310 (CTES, SPF); Hensold et al. CFCR 3526 (CTES, SPF); Pirani et al. CFCR 12878 (CTES, SPF); Prado et al. CFCR 12027 (CTES, SPF).

Espécie polimorfa com relação ao indumento e morfologia da folha; freqüente na América do Sul, se estendendo pela América Central (Costa Rica e Nicarágua) até o México (Vera Cruz). Não ocorre no sul do Brasil, sendo comum nas demais regiões. Em Grão-Mogol vive à margem dos Rios Itacambiruçu e das Mortes e nas beiras de estradas. Floresce e frutifica o ano todo. Caracteriza-se pelo hábito prostrado e pelos mericarpos verrucosos e longamente rostrados no ápice (Fig. 2. I-J ).

3.3 Pavonia garckeana Gürke in Mart., Fl. bras. 12(3): 496, t.92. 1892 .

Subarbustos 1-1,5 m alt.; ramos esverdeados a levemente vináceos, tomentosos a glabrescentes, tricomas predominantemente estrelados. Folhas de lâminas 3-9,5 cm compr., 1,5-5 $\mathrm{cm}$ larg., discolores, ovadas, ápice agudo a acuminado, base cordada, margem irregularmente serreada; pecíolos 1-4 cm compr.; estípulas 5-7 mm compr. Flores vistosas, geralmente aos pares, às vezes formando umbelas; epicálice com 4-5 bractéolas, 1,4-2 cm compr., ovadas a suborbiculares, base cordada; cálice 8-14 mm compr., cupuliforme; pétalas 2,5$4,5 \mathrm{~cm}$ compr., róseas com mancha basal e nervuras vináceas; tubo estaminal 1,5-2,3 cm compr., ereto, partes livres de estames distribuídas em grupos ao longo do tubo. Mericarpos obovóides, verrucosos, mucronados; sementes obovóides, vináceas, longitudinalmente estriadas. (Fig. 2. R-U ).

Cordeiro et al. CFCR 974 (MAC, SPF); Esteves et al. CFCR 13306 (CTES, SPF); Freire-Fierro et al. CFCR 12387 (SPF); Hatschbach 41310 (CTES, HB, MBM, NY, SPF, UEC); Zappi et al. CFCR 12086 (SPF).

Bolívia e Brasil, nas regiões Nordeste, Centro-Oeste e Sudeste, desde a Bahia, passando por Mato Grosso e Minas Gerais até São Paulo. Em Grão-Mogol ocorre no cerrado e no carrasco, em solo arenoso com afloramento rochoso, entre 700 a $850 \mathrm{~m}$ alt. Floresce e frutifica o ano todo. Dentre as espécies que ocorrem em Grão-Mogol, $P$. garckeana e $P$. grazielae são as únicas a apresentarem o epicálice formado por 4 a 7 bractéolas ovadas de base cordada. Entretanto são bastante distintas, especialmente pela coloração das pétalas, distribuição das partes livres dos estames no tubo estaminal, forma do cálice e das sementes e pela presença de estrias nas sementes de $P$. garckeana (Fig. 2U).

3.4. Pavonia grazielae Krapov., Revta. brasil. bot. 1: 89 . 1978.

Arbustos 1-3 m alt., viscosos, odoríferos; ramos pubescentes a glabrescentes, tricomas predominantemente glandulares. Folhas de lâminas 3,8-10 cm compr., 2,7-9,6 cm larg., largo-ovadas a orbiculares, base cordada, margem irregularmente serreada a quase lisa, nigrescentes na face adaxial, glauca na face abaxial; pecíolos 2-6,5 cm compr.; estípulas 2-5 mm compr., filiformes. Flores vistosas; pedicelos 2,56,5 cm compr.; epicálice com 4-7 bractéolas, 1,1-2,8 cm compr., ovadas, base arredondada a cordada; cálice 1,1-1,7 cm compr., tubuloso-cupuliforme; pétalas 2,5-3,8 cm compr, amarelas com mancha basal vinácea; tubo estaminal 2,4-3,6 cm compr., partes livres dos estames distribuídas na porção apical do tubo. Mericarpos subovóides, múticos; sementes reniformes, lisas, vináceas. (Fig. 2. N-Q).

Cordeiro \& Mello-Silva CFCR 10023 (MAC, SPF); Esteves et al. CFCR 13315 (CTES, SPF); Esteves et al. CFCR 3461, 13457 (SPF); Harley et al. CFCR 6479 (CTES, SPF); Harley et al. 25062 (SPF); Hensold et al. CFCR 3533 (CTES, MAC, SPF); Mello-Silva et al. CFCR 9810 (MAC, SPF); Mello-Silva et al. 474, 1441 (CTES, SPF); Mello-Silva et al. 1441 (SPF); Pirani et al. CFCR 8340, 12864 (CTES, SPF); Prado et al. CFCR 12032 (SPF); Silva et al. CFCR 12530 (SPF); Simão-Bianchini et al. CFCR 12995 (CTES, SPF).

Endêmica de Grão-Mogol, onde vive em altitudes entre 750 a 1300 m s.m., no campo rupestre, crescendo entre fendas de grandes rochas ou sobre as rochas, no carrasco e no cerrado, em solo areno-pedregoso. A espécie é facilmente reconhecida no campo pela consistência viscosa e ordor característico, semelhante ao de laranja podre. Entre as espécies que ocorrem em Grão-Mogol, P. grazielae se assemelha com $P$. garckeana na morfologia do epicálice, porém difere, sobretudo, pelos caracteres da corola, tubo estaminal e dos mericarpos, conforme foram mencionados na chave.

3.5. Pavonia rosa-campestris A. St.-Hil., Fl. bras. mer. 1: 236, t. $46,1827$.

Subarbustos $0,40-1 \mathrm{~m}$ alt.; ramos pubérulo-estrelados mais tricomas simples, esparsos. Folhas de lâminas 1,5-4,6 cm compr., 1,1-3,6 cm larg., coriáceas, ovadas, ápice agudo, base cordada, margem serreada, ciliada; pecíolos 1-3,5 cm compr. Flores vistosas, rotáceas; epicálice com 11-16 bractéolas, 1-1,9 cm compr., elípticas, longamente ciliadas; cálice 4-6 $\mathrm{mm}$ compr., lobos longamente ciliados; pétalas $1,5-2,5 \mathrm{~cm}$ compr., rosa passando a vermelha, com mancha basal branca; tubo estaminal 5-8 mm compr., rosado, inclinado, partes livres dos estames distribuídas nos 2/3 apicais do tubo. Mericarpos obovóides, verrucosos, rugosos, rostrados, rostros ca. $1 \mathrm{~mm}$ compr.; sementes reniformes, lisas. (Fig. 2. A-E).

Cerati et al. 252 (SP, SPF); Esteves et al. CFCR 13343 (CTES, SPF); Markgraf et al. 3335 (HB, BHMH); Martinelli et al. 11204 (BHCB); Mello-Silva et al. CFCR 11559 (SPF); Silva et al. CFCR 12696 (SPF).

Espécie com distribuição no Brasil, nas regiões Nordeste (Bahia, Piaui), Sudeste (Minas Gerais) e Centro-Oeste (Distrito Federal, Goiás, Mato Grosso, Rondônia). Em Grão-Mogol ocorre nos cerrados e carrascos em solo areno-pedrego- 
so. Floresce e frutifica o ano todo. É facilmente distinta pelas folhas coriáceas, ovadas de base cordada e margem serreadociliada e pelas flores vistosas, rotáceas, com tubo estaminal inclinado e menor que a corola (Fig. 2A). Se assemelha com P. piauhyensis que tem distribuição no Piaú e Bahia e difere na morfologia das flores e por apresenta folhas lobadas e não ciliadas.

\subsection{Pavonia sidifolia Kunth, Nov. gen. pl. 5: 283. 1823.}

Subarbustos ca. $40 \mathrm{~cm}$ alt., eretos; ramos delgados, tomentosos, tricomas estrelados, simples e glandulares. Folhas de lâminas 4,2-7 cm comp., 2,3- 4,6 cm larg., ovadas, ápice agudo, base cordada, margem crenado-serreada; pecíolos 1-3 cm compr. Flores solitárias; epicálice com 6-8 bracté- olas elípticas; cálice cupuliforme, 5-7 mm comp., curtamente ciliado; pétalas amarelas com mancha basal vinácea; tubo estaminal ca. $9 \mathrm{~mm}$ comp., menor que a corola, partes livres dos estames distribuídas por todo o tubo. Mericarpos múticos, obovóides, em geral verrucosos; sementes obovóides, longitudinalmente estriadas, glabras, vináceas. (Fig. 2. K-M).

Silva et al. CFCR 12573 (SPF).

Distribuição neotropical, freqüente em todas as regiões do Brasil. Floresce e frutifica o ano todo. Pode ser confundida com $P$. cancellata pela coloração das pétalas, entretanto esta última possui hábito prostrado, mericarpos rostrados e sementes lisas, além da morfologia do epicálice bastante distinta (Fig. $2 \mathrm{H} \mathrm{e} \mathrm{K}$ ).

\section{Peltaea (Presl.) Standley}

Subarbustos eretos. Indumento de tricomas estrelados. Folhas de lâminas inteiras a sublobadas, sem nectários. Flores vistosas; epicálice presente, bractéolas livres entre si, peltadas, diferenciadas morfologicamente em pé e lâmina; pétalas obovadas; tubo estaminal 5-denteado no ápice, inserto; ovários 5-carpelar, 5-locular, lóculos 1-ovulados; estiletes 10, com tricomas glandulares; estigmas capitados. Fruto esquizocárpico; mericarpos 5, deiscentes, sem acúleos; sementes 1 por mericarpo, reniformes.

\subsection{Peltaea obsita (Mart. ex Colla) Krapov. \& Cristóbal,} Kurtziana 2: 165. 1965.

Subarbustos ca. $1 \mathrm{~m}$ alt.; ramos com tricomas estrelados amarelos. Folhas de lâminas 3,5-6,5 cm compr., 3-5 cm larg., levemente discolores, inteiras a subtrilobadas, ovadas, ápice agudo, base arredondada a cordada, margem irregularmente serreada, com tricomas estrelados em ambas as faces; pecíolos 3-3,5 cm compr.; estípulas 3-5 mm comp. Flores agrupadas na parte apical de pequenos ramos axilares; epicálice com 10 bractéolas, pé 3-3,5 mm compr., lâmina 2,5-3 mm compr.; cálice 6-7 mm compr.; pétalas 1,8-2 cm comp., inteiramente amarelas; tubo estaminal 1,5-1,7 cm, partes livres dos estames distribuídas em 4 grupos ao longo do tubo. Me- ricarpos ca. $3 \mathrm{~mm}$ compr., lisos, glabros; sementes glabras. (Fig. 1. D-H ).

Mello-Silva et al. 762 (CTES, SP, SPF).

Espécie distribuída no Paraguai, Bolívia e no Brasil onde ocorre nas regiões Centro Oeste, Sudeste e Sul, até o Paraná, no campo rupestre e cerrado. Em Grão-Mogol foi encontrada próximo à nascente do Rio Ventania, em solo arenoso. Além da forma das bractéolas do epicálice (Fig. 1 F-G) e da coloração das pétalas, $P$. obsita é distinta por apresentar o tubo estaminal menor que a corola e as partes livres dos estames distribuídas em 4 grupos.

\section{Sida L.}

Ervas, subarbustos ou arbustos, indumento de tricomas estrelados, simples e glandulares, ocasionalmente viscosos. Folhas de lâminas inteiras ou sublobadas, 1-7-palmatinérveas. Flores solitárias axilares e/ou inflorescências axilares ou terminais; epicálice ausente; cálice 5-lobado, em geral 10-costado na base e plicado no botão; pétalas obovadas, diversamente coloridas; tubo estaminal com partes livres dos estames distribuídas na sua porção apical; carpelos 5-10, uniovulados; estiletes 5-10; estigmas capitados. Fruto esquizocárpico; mericarpos 5-10, múticos ou aristados, em geral nervado-reticulados na porção dorso-basal e nas faces laterais, porção basal indeiscente, apicalmente deiscente ou indeiscente; semente 1 por mericarpo, glabra, exceto ao redor do hilo. 


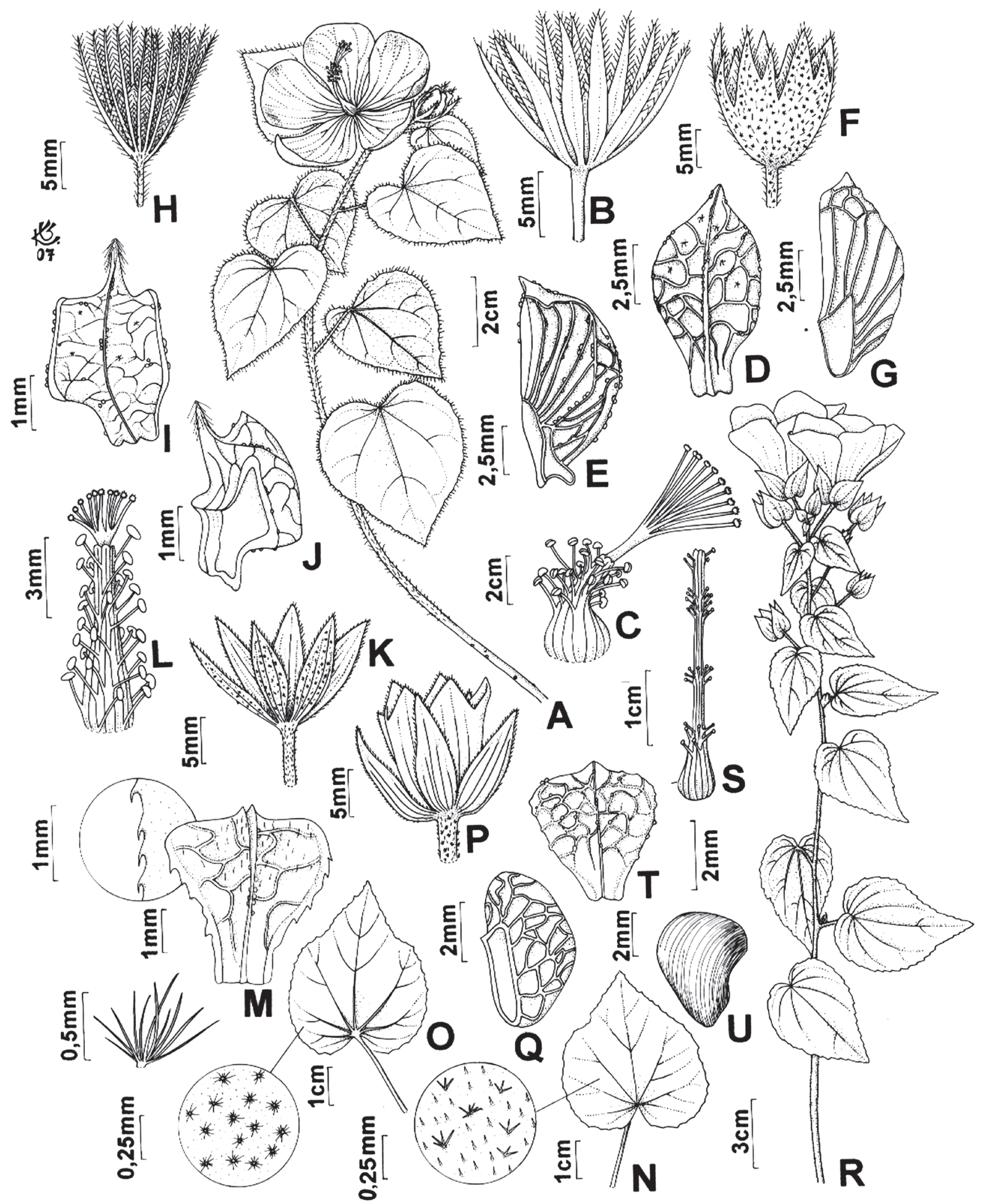

Fig. 2. MALVACEAE. A-E. Pavonia rosa-campestris: A. Ramo com flores. B. Epicálice. C. tubo estaminal. D. Mericarpo, vista dorsal. E. Mericarpo, vista lateral. F-G. P. aschersoniana: F. Cálice, G. Mericarpo, vista lateral. H-J. P. cancellata: H. Epicálice e cálice. I. Mericarpo, vista dorsal. J. Mericarpo, vista lateral. K-M. P. sidifolia: K. Epicálice. L. Tubo estaminal. M. Mericarpo, vista dorsal. N-Q. P. grazielae: N-O. Folhas, faces adaxial e abaxial. P. Epicálice e cálice. Q. Mericarpo, vista látero-dorsal. R-U. P. garckeana: R. Ramo com flores. S. Tubo estaminal. T. Mericarpo, vista dorsal. U. semente. (Extraído de Esteves 2001). 
5.1. Sida angustissima A. St.-Hil., Fl. bras. merid. 1: 179. 1827.

Subarbustos $0,30-1 \mathrm{~m}$ alt.; ramos pubescentes a glabrescentes, tricomas estrelados. Folhas de lâminas 2-6 cm compr., 2-3 mm larg., lineares a estreitamente elípticas, 1-nérveas, ápice agudo, base aguda, margem serreada; pecíolos 3-5 $\mathrm{mm}$ comp. Flores solitárias, axilares; cálice 4-6 mm compr.; pétalas amarelas a alaranjadas; tubo estaminal menor que as pétalas. Mericarpos 7-8, 2-aristados no ápice; aristas eretas, divergentes, com tricomas simples retrorsos; sementes trígono-globosas. (Fig. 1. S).

Esteves et al. CFCR 13264 (SPF), CFCR 13309 (CTES, SPF); Oliveira et al. CFCR 13164 (CTES, SPF); Silva et al. CFCR 12386 (CTES, SPF).

Espécie com distribuição nas regiões Nordeste e Sudeste do Brasil. Em Grão-Mogol ocorre no carrascal, em solo arenoso com afloramento rochoso. Floresce e frutifica o ano todo. Pode ser facilmente reconhecida pelas folhas estreitas, lineares a elípticas, uninérveas, com margem serreada e mericarpos longamente aristados (Fig. 1S). Pelas folhas lineares é geralmente confundida com $S$. linifolia Cav., porém esta última possui folhas trinérveas de margem lisa e mericarpos múticos.

5.2. Sida aurantiaca A. St.-Hil., Fl. bras. merid. 1: 185, t. 35. 1827.

Arbustos ca. 1,5 m alt.; ramos pubescentes, tricomas glandulares, bulbosos na base, mais tricomas simples, esparsos. Folhas de lâminas 7-20 mm compr., 4-9 mm larg., ovadas, ápice agudo a obtuso, base levemente cordada, margem serreada, 5-palmatinérveas, pubescentes; pecíolos 6-12 mm comp. Flores solitárias, axilares; pedicelos 1-1,5 cm comp.; cálice cupuliforme, externamente com tricomas glandulares bulbosos na base; pétalas alaranjadas; tubo estaminal menor que as pétalas; estiletes 5. Mericarpos 5, múticos, pubescentes na porção apical, tricomas glandulares bulbosos na base; sementes trígono-globosas.

\section{Hatschbach et al. 41230 (CTES).}

Sudeste do Brasil (Minas Gerais). Em Grão-Mogol foi encontrada no campo rupestre. Caracteriza-se principalmente pelo indumento constituído de tricomas glandulares bulbosos na base.

\subsection{Sida cerradoensis Krapov., Bonplandia 3(2): 19. 1969.}

Ervas ca. $70 \mathrm{~cm}$ alt., ramos pubescentes, tricomas estrelados mais tricomas glandulares e simples esparsos. Folhas de lâminas 17-21 mm compr., 7,5-9 mm larg., oblongo-ovadas, ápice agudo, base arredondada, margem serreada e geralmente vinácea, 5-palmatinéveas; pecíolos 3-5 $\mathrm{mm}$ comp. Flores formando corimbos no ápice de pequenos ramos; pedicelos até $10 \mathrm{~mm}$ comp.; cálice 7-8 mm compr., cupuliforme, lobos vináceos na margem; pétalas amarelo-alaranjadas; tubo estaminal menor que as pétalas; estiletes 10 . Mericarpos 10, com longos tricomas simples na porção apical, 2-aristados, aristas 2,5-3,3mm compr., eretas, com tricomas simples retrorsos; sementes trígono-globosas. (Fig. 1. T ).

\section{Hatschbach et al. 54949 (CTES).}

Espécie distribuída desde o Pará até o Paraná e em Mato Grosso. Em Grão-Mogol ocorre no campo rupestre degradado, em solo arenoso. É facilmente reconhecida por apresentar a margem das folhas e dos lobos do cálice vináceos.

\subsection{Sida cordifolia L., Sp. pl. 2: 684. 1753.}

Subarbustos ca. $80 \mathrm{~cm}$ alt.; ramos pubescentes a tomentosos, com tricomas estrelados e simples, glabrescentes. Folhas de lâminas 2-3 cm compr., 1,7-2 cm larg., ovadas, ápice obtuso a agudo, base cordada, margem crenado-serreada, 5-7 palmatinérveas; pecíolos $0,8-1,5 \mathrm{~cm}$ compr.; estípulas 5-9 mm compr., filiformes. Flores solitárias axilares e/ou formando corimbos em pequenos ramos axilares; cálice 6-7 $\mathrm{mm}$ compr.; pétalas amarelas; tubo estaminal menor que as pétalas, amarelo; estiletes 10. Mericarpos 10, 2-aristados, aristas eretas, divergentes, com pequenos tricomas simples retrorsos; sementes trígono-globosas (Fig. 1. N-R).

\section{Esteves et al. CFCR 13313 (SPF).}

Pantropical, comum em lugares abertos e degradados. Em Grão Mogol ocorre em área perturbada. Floresce e frutifica o ano todo. Caracteriza-se pelas folhas ovadas de base cordada, flores reunidas em corimbos dispostos em pequenos ramos axilares e mericarpos em número de 10, com duas aristas longas, eretas e divergentes (Fig. 1. P-Q).

\subsection{Sida sp. 1}

Subarbustos 40-70 cm comp. alt.; ramos tomentosos, tricomas estrelados e glandulares, mais longos tricomas simples, patentes, esparsos, glabrescentes e então vináceos. Folhas de lâminas 1-3,5 cm compr., 0,8-2 cm larg., verde-claras em ambas as faces, ovadas, ápice agudo a obtuso, base cordada, margem crenado-serreada, 5-7-palmatinérveas, velutinas a vilosas, tricomas estrelados mais tricomas glandulares esparsos em ambas as faces; pecíolos 10-18 mm comp. Flores solitárias axilares ou agrupadas no ápice de pequenos ramos; pedicelos 1,5-1,8 cm compr., delicados; cálice 4-6mm compr., cupuliforme; pétalas amarelas a alaranjadas; tubo estaminal menor que as pétalas; estiletes 5. Mericarpos 5, múticos, pubescentes e curtamente sulcados na porção apical, tricomas estrelados; sementes piriformes. (Fig. 1. U-V) 
Esteves et al. CFCR 13333 (CTES, SPF); Pirani et al. CFCR 11362 (CTES, SP, SPF); Simão-Bianchini et al. CFCR 12830 (CTES, SP, SPF), CFCR 12891 (CTES, K, SP, SPF).

Conhecida apenas pelas coleções de Grão-Mogol, onde ocorre nos campos e cerrados, em solo arenoso-pedregoso, entre arbustos. Distingue-se pelo indumento tomentoso a viloso, constituído predominantemente de tricomas estrelados mais tricomas simples e glandulares e pelas flores longamente pediceladas. Dentre as espécies que ocorrem em GrãoMogol, Sida sp.1 se assemelha a $S$. aurantiaca por ambas apresentarem 5 mericarpos, entretanto, esta última, além de possui o indumento pubescente formado em sua maioria de tricomas glandulares, difere com relação às dimensões das folhas.

\subsection{Sida sp. 2}

Subarbustos 30-40 cm alt.; ramos com indumento de tricomas estrelados pequenos, mais tricomas glandulares e tricomas estrelados maiores, esparsos. Folhas de lâminas 24$55 \mathrm{~mm}$ compr., 7-19 mm larg., às vezes discolores, oblongas, ápice agudo, base truncada, às vezes subcordada, margem serreada, 5-palmatinérveas, face adaxial com tricomas estrelados e glandulares esparsos, glabrescente, face abaxial com indumento denso de tricomas estrelados e glandulares esparsos; pecíolos 4-9 mm comp. Flores em corimbos no ápice de pequenos ramos, às vezes solitárias, axilares; pedicelos 5-10 mm comp.; cálice 6-7 mm compr., lobos ovados, ápice agudo-apiculado; pétalas amarelas a alaranjadas; tubo estaminal menor que as pétalas; estiletes (6-)8. Mericarpos (6-)8, múticos, nigrescentes, face dorsal com duas nervuras longitudinais proeminentes submarginais, longamente sulcada; sementes piriformes. (Fig. 1. L-M).

Silva et. al. 12397 (CTES, SP, SPF).

Material adicional: Minas Gerais, Diamantina, na direção de Medanha, Arbo et al. 5092 (SPF, CTES).

Conhecida pelas coleções de Grão-Mogol e Diamantina, onde cresce no campo rupestre e no carrasco, em solo arenoso com afloramentos rochosos. Floração e frutificação nos meses de dezembro e fevereiro. Dentre as espécies de Sida ocorrentes em Grão-Mogol que possuem frutos com mais de 5 mericarpos, Sida sp. 2 é a única que apresenta os mericarpos múticos. A espécie se distingue, também, pelas folhas oblongas, às vezes discolores e mericarpos em número de 6 a 8, longamente sulcados na porção apical e com duas nervuras longitudinais submarginais na face dorsal (Fig. 1M).

\section{Urena L.}

Subarbustos ramificados. Folhas de lâminas polimorfas, inteiras a lobadas, com 1 ou raramente 3 nectários na base das nervuras primárias na face abaxial. Flores isoladas, axilares, freqüentemente formando glomérulos terminais; epicálice com 5 bractéolas, unidas entre si; cálice 5-lobado, cupuliforme; pétalas róseas a purpúreas, sem mancha basal; tubo estaminal 5-denteado na porção apical, partes livres dos estames distribuídas ao longo do tubo; ovário 5-carpelar, carpelos uniovulados; estilete 10. Mericarpos 5, trígono-obovóides, face dorsal lisa ou aculeada, faces laterais planas e lisas; sementes reniformes.

\subsection{Urena lobata L., Sp. pl., p. 692. 1753.}

Subarbustos ca. $3 \mathrm{~m}$ alt.; ramos pubescentes, tricomas estrelados. Folhas de lâminas 3-5,2 cm comp., 2,2-4,6 cm larg., 3-lobadas, sinuadas, base subcordada a arredondada, margem serreada; nectário 1 , sobre a nervura média na face abaxial, uniaperturado, oblongo, amarelado; pecíolos 1,4-2,8 cm comp. Flores solitárias axilares ou em grupo de 3-4 no ápice dos ramos; epicálice e cálice acrescentes no fruto, lobos eretos, epicálice 7-8 mm comp., cálice 7-8,5 mm comp., pétalas inteiramente róseas. Mericarpos 4-5 mm comp., face dorsal híspida, com tricomas estrelados e acúleos agudos, fa- ces laterais pubérulas, tricomas estrelados; sementes glabras. (Fig. 1. J-K ).

\section{Zappi et al. CFCR 12990 (SPF).}

Pantropical, amplamente distribuída na América do Sul. Em Grão-Mogol foi encontrada em área perturbada, a margem de riacho. Floresce e frutifica o ano todo. Caracteriza-se pelas folhas de lâminas inteiras a lobadas, com um nectário sobre a nervura média na face abaxial e pelos mericarpos aculeados na face dorsal. 